\title{
Factors Affecting Consumers' Choice in Consumption of Organic Vegetables and Methods Used to Avoid Consumption of Unhealthy Foods in Tanzania
}

\author{
Willbroad Kawemama, ${ }^{1,}$, Jovin Mugula ${ }^{1}$, Alex Wostry ${ }^{2}$, Janet Maro \\ ${ }^{1}$ Department of Food Technology, Nutrition and Consumers Sciences, Sokoine University of Agriculture, Morogoro, Tanzania \\ ${ }^{2}$ Sustainable Agriculture Tanzania Organization, Morogoro, Tanzania
}

Email address:

willbroadkawemama@gmail.com(W.Kawemama)

${ }^{*}$ Corresponding author

\section{To cite this article:}

Willbroad Kawemama, Jovin Mugula, Alex Wostry. Factors Affecting Consumers' Choice in Consumption of Organic Vegetables and Methods Used to Avoid Consumption of Unhealthy Foods in Tanzania. International Journal of Nutrition and Food Sciences. Vol. 7, No. 2, 2018, pp. 71-80. doi: 10.11648/j.ijnfs.20180702.15

Received: January 29, 2018; Accepted: March 21, 2018; Published: April 11, 2018

\begin{abstract}
In the previous decades, there has been an upsurge of use of pesticides on food produces. Many consumers now perceive or are knowledgeable that consumption of organic vegetables is healthier than consuming their corresponding items. A cross sectional study was done to assess the factors affecting consumers' choice in consumption of organic vegetables and methods used to avoid consumption of unhealthy foods in Morogoro and Kinondoni municipalities. A total of 200 paticipants half from each segment were interviewed using a constructed and pretested structured questionnaire. However, the analysis was done to 192 residents, half from each study segment. Data analysis was done through SPSS version 20. Scale liability was tested with Cronbach alpha. Multiple regression analysis was conducted to determine factors that affected the consumers' choice and identify as well as the approaches used by them to avoid the consumption of unhealthy foods. To avoid consumption of foods that were perceived perilous, physical appearance was a common method used by most $(52 \%, \beta=0.493)$ consumers compared to reading product labels $(45.3 \%, \beta=0.296)$, asking product information $(38 \%, \beta=0.434)$ and product tasting $(26 \%, \beta=0.146)$. The low purchasing and consumption rates of organic vegetables were significantly different $(P<$ $0.05)$, affected by their perceived low shelf life $(\beta=0.108)$, lack of uniqueness $(\beta=0.071)$ and unavailability in the market $(\beta$ $=0.032$ ). Most organic food growers $(97 \%)$ needed an external participatory guarantee system for liable market so that producers and investors cooperate with organic growers for business-oriented aspects.
\end{abstract}

Keywords: Organic Vegetables, Factor, Methods and Consumers

\section{Introduction}

Over the past two decades, there has been an increase in consumers' awareness and concern for safe, nutritious and high quality food. This is because food intake affects the wellbeing of every individual in health promotion and prevention of diseases [38]. However, the food that is available today in different parts of the world is not safe; its consumption does not enhance health, and it does not guarantee nutrition security. Overuse of pesticides and fertilizers by farmers has resulted to land degradation that affects food production [41]. Pesticides have been widely used in protecting crops against pest infestation; however, the amount of pesticide residues should be minimized to safe levels in order to ensure the supply of safe produce [44]. There is a need to change some of the practices in the food production and distribution systems in order to ensure the production and supply of safe food [48]. Therefore, to ensure the production and consumption of safe and nutritious foods, many producers and consumers have opted to use organic products.

Organic agriculture is a system for crops, livestock and fish farming that emphasizes on environmental protection and use of natural farming technique [10]. It is concerned with the food chain from farm to fork, and excludes the use of artificial products, such as genetically modified organisms 
(GMOs) and certain external agricultural inputs such as pesticides, veterinary drugs, additives and fertilizers [10]. One comparative study has shown that most of the organic products have lower nitrate content, less pesticide residues, higher levels of vitamin $\mathrm{C}$, phenolic compounds, and omega3 fatty acids and conjugated linoleic in milk produced by organically raised animals [14].

\subsection{Development of Organic Farming in Tanzania}

Tanzanian farmers, both before and after independence, practiced low-input agriculture, known as traditional farming, using animal manure from ruminants and chickens [30]. In the year 2001, the government introduced interventions that aimed at improving food security, rural household income and social- economic development [30]. The intervention included the introduction of agricultural inputs such as intensive use of industrial fertilizers, pesticides and hybrid seeds [21]. In order to speed up early adopters of one of these agricultural inputs, the government introduced significant agricultural input subsides. As a result of this, there was an improvement in agricultural production. A report from Pesticide and Poverty report Tanzania [35], showed an increase in the importation of pesticides from 500 tons to 2500 tons from the year 2000 to 2003, unfortunately the subsidies to farmers were reduced due to mismanagement and corruption, and this led to decreased production [17]. With a decreased use of pesticides and fertilizers in the farms because of the high price, there has been an increase in the pest infestation in the fields [32-33]. [27], assert that traditionally, there were several natural pests and disease control strategies, which acted as plant strengtheners such as comfrey, leucaena leucocephala, hot peppers ordinary wood ash, bar soap, onions and garlic. Also pest killers included pyrethrum, neem tree and pawpaw leaves and others; however, currently the use of traditional repellants has been replaced by modern chemicals [34].

\subsection{World Organic Production and Economical Value}

Organic farming has become one of the fastest growing sectors in agriculture, from 2005-2011, the total area that was used for farming increased from $3.6 \%$ to $5.5 \%$, almost 31 million hectares [50]. Currently, 43 million hectares are used for organic farming [11]. Globally, there have been significant market increments of organic products. The market shares have increased three folds (from 14 billion euros in 2000 to 45 billion euros in 2010) [50].

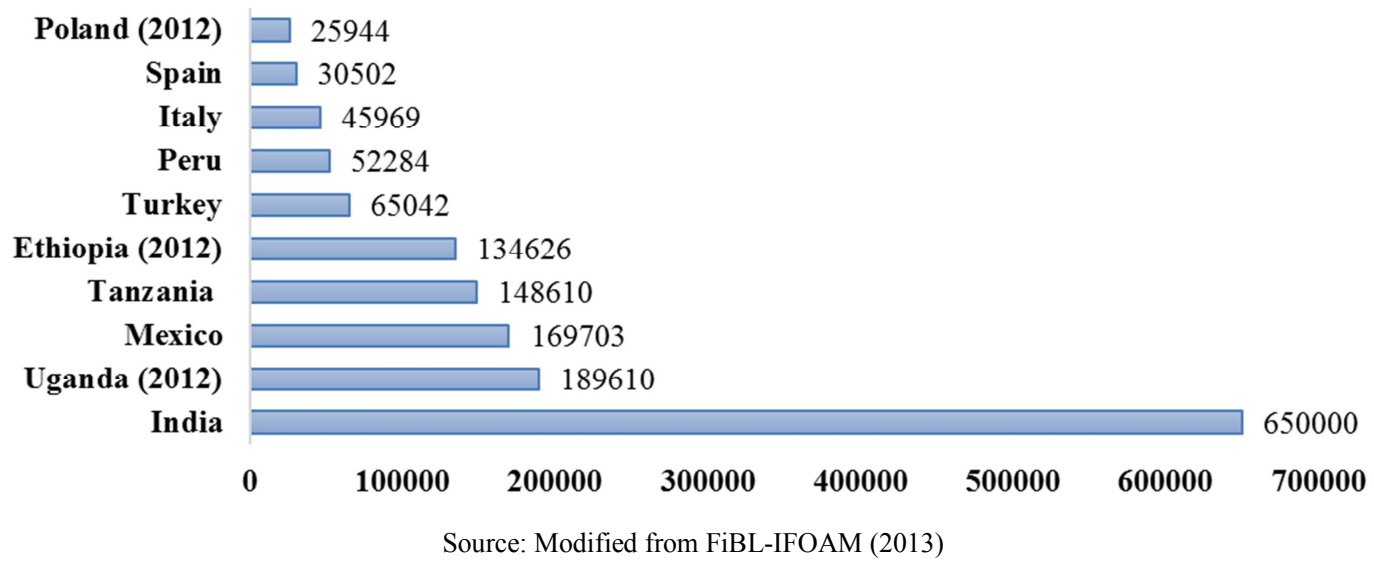

Figure 1. Top ten producers of organic products (tons) in the world by 2013.

Worldwide, countries which are the leading producers of organic vegetables include India (650 000 tons), Uganda (189 610 tons) and Mexico (169 703 tons) by 2014 (Figure. 1). The leading continents for organic producers include Asia, Africa and Europe (Figure. 2). Tanzania is Africa's second producer of organic food after Uganda (Figure. 1). Worldwide the country was ranked the fourth in production and exportation of organic food (148610 metric tons), and this contributed to 9898960 euros [40]. There has been an increase in the total area that is used for organic farming (from 72188 ha in the year 2008 to 186537 ha in 2012) [2].

The growing consumer demand for organic food emerged mainly out of health and environmental concerns, which were intensified by food scandals and scares [43]. This may be explained by the higher prices for organic vegetables, which make them unaffordable to some consumers [49].

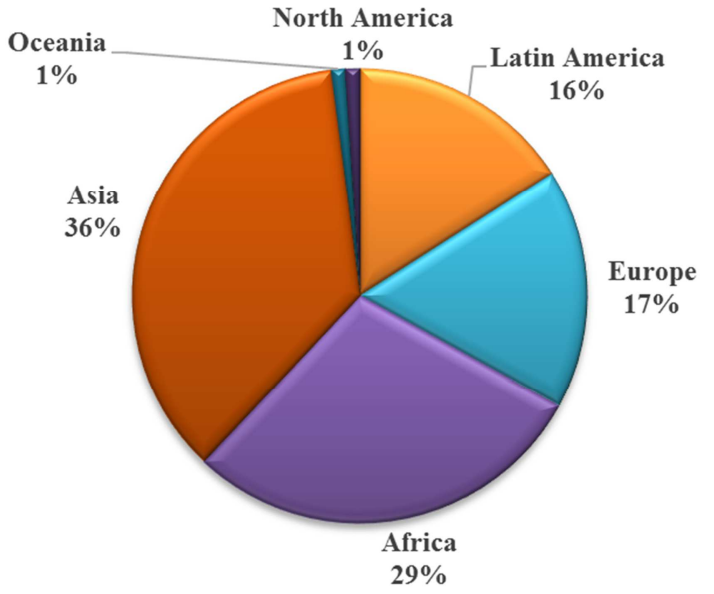

Source: Modified from FiBL-I OAM (2013)

Figure 2. Organic producers by region year 2013. 


\section{Methodology}

\subsection{Study Area and Population}

The study was conducted in Kinondoni municipal Dar es salaam and Morogoro municipal in Morogoro region Tanzania. The study population comprised of farmers and buyers who were involved in the shopping of food products from the market. All adult farmers (people aged above 18 years old) who were willing to be involved in this study were involved, and they were given with a concert form to sign for their affirmation. Those who were not willing to participate in this study could not be involved. The other involved people in this study were food buyers who were neither involved in farming activities. More than $50 \%$ of the involved population in this study were famers who were directly involved in farming activities.

\subsection{Sample Size and Techniques}

The constructed checklist was used for selecting the wards purposively, according to their socioeconomic activities. More than half of respondents in Morogoro Municipality were selected purposely - as were directly involved with organic farming. Such selection was purposely conducted, in order for them to view their success and challenges emanating from growing of organic vegetable in Morogoro. While in Kinondoni were selected by consideration of the huge market of organic vegetables. However, data were collected from 192 residents, half from each study segment. And were analyzed by using SPSS windows version 16.0, descriptive statistics such as frequencies, percentages and Chi square $\left(\mathrm{X}^{2}\right)$ were computed to determine relationship among variables using separation of means.

\section{Results}

\subsection{Socioeconomic and Demographic Characteristics of the Farmers and Consumers}

\subsubsection{Sex of Farmers and Consumers}

The socioeconomic and demographic characteristics of the respondents are indicated in Table 1. The results showed that, more than half $(57.8 \%)$ of the interviewed respondents from both sites were females, while males were only $42.2 \%$.

\subsubsection{Education Level}

About $7.3 \%$ of the respondents had no formal education while the least had undergone formal education. The highest attained education level was primary with $50 \%$ of respondents. The results showed that only $15.6 \%$ of the formally educated people achieved college education.

\subsubsection{Age of the Respondents}

About $72.4 \%$ of the respondents were under 45 . Most of the respondents fall in the age group 20 and 34 years. The results also indicated that, in both locations the number of studied individuals at the age between $20-34$ was actually higher compared to other age groups (Table 1). Morogoro Municipality had many respondents compared to its counterpart's location. However, at the age group of $35-44$ and 45- 54 the number of people in Kinondoni was high compared to Morogoro Municipality.

\subsubsection{Income Levels of Consumers and Farmers}

The results showed that, $26 \%$ of the respondents earned an average income of less than 100000 TSZ per months. The study revealed that only $2.1 \%$ of the respondents had an average income of more than one million TZS per month. The results showed that, none of the interviewed individuals in Morogoro Municipality had an average of more than a million per month (Table 1). Most of them (37.5\%) had an average income (in Morogoro Municipality) of TZS 100000 to 400000 per month. About a quarter of these people in both locations had an average income of less than TZS 100000 TZS per month. Further, it was observed that the majority of those who had an average income of less than TZS 100000 per month were in the Morogoro Municipality (Table 1).

\subsubsection{Occupational of Respondents}

More than half $(59.4 \%)$ of the studied population in Morogoro Municipality were farmers. The rest in these areas were self-employed in a non - farming sector like petty business or worked in the formal sector (including government and private sectors). The results also showed that, about $9.4 \%$ and $24 \%$ of the interviewed people in Morogoro Municipality and Kinondoni Municipality, correspondingly, had no specific work to do. The prevalence of un-employment in the studied location was $24 \%$ with Kinondoni Municipality being higher (14.6\%) compared to its counterpart location. There was no one among the interviewed individuals in Kinondoni Municipality who mainly engaged in farming activity.

Famers and other people who were self-employed accounted to about $59 \%$ and $74 \%$, in Morogoro and Kinondoni municipalities respectively. The results also indicated that, people who worked in the formal sector in Kinondoni Municipality were three times more than those in Morogoro Municipality. Similarly, results also showed that the percent of people who were self-employed in Kinondoni Municipality were also three times more than those who were working in the same sector in Morogoro Municipality.

Table 1. Socio-demographic characteristics of the studied population.

\begin{tabular}{|c|c|c|c|c|c|c|c|}
\hline \multirow{3}{*}{ Variable } & \multirow{3}{*}{ Categories } & \multicolumn{4}{|c|}{ Location } & \multirow{2}{*}{\multicolumn{2}{|c|}{ Total }} \\
\hline & & \multicolumn{2}{|c|}{ Morogoro } & \multicolumn{2}{|c|}{ Kinondoni } & & \\
\hline & & $\mathrm{n}=96$ & $\%$ & $\mathrm{n}=96$ & $\%$ & $\mathrm{~N}=192$ & $\%$ \\
\hline \multirow{2}{*}{ Sex } & Male & 35 & 36.5 & 46 & 47.9 & 81 & 42.2 \\
\hline & Female & 61 & 63.5 & 50 & 52.1 & 111 & 57.8 \\
\hline \multirow{2}{*}{ Education } & No Formal Education & 6 & 6.3 & 8 & 8.3 & 14 & 7.3 \\
\hline & Primary Education & 65 & 67.7 & 31 & 32.3 & 96 & 50.0 \\
\hline
\end{tabular}




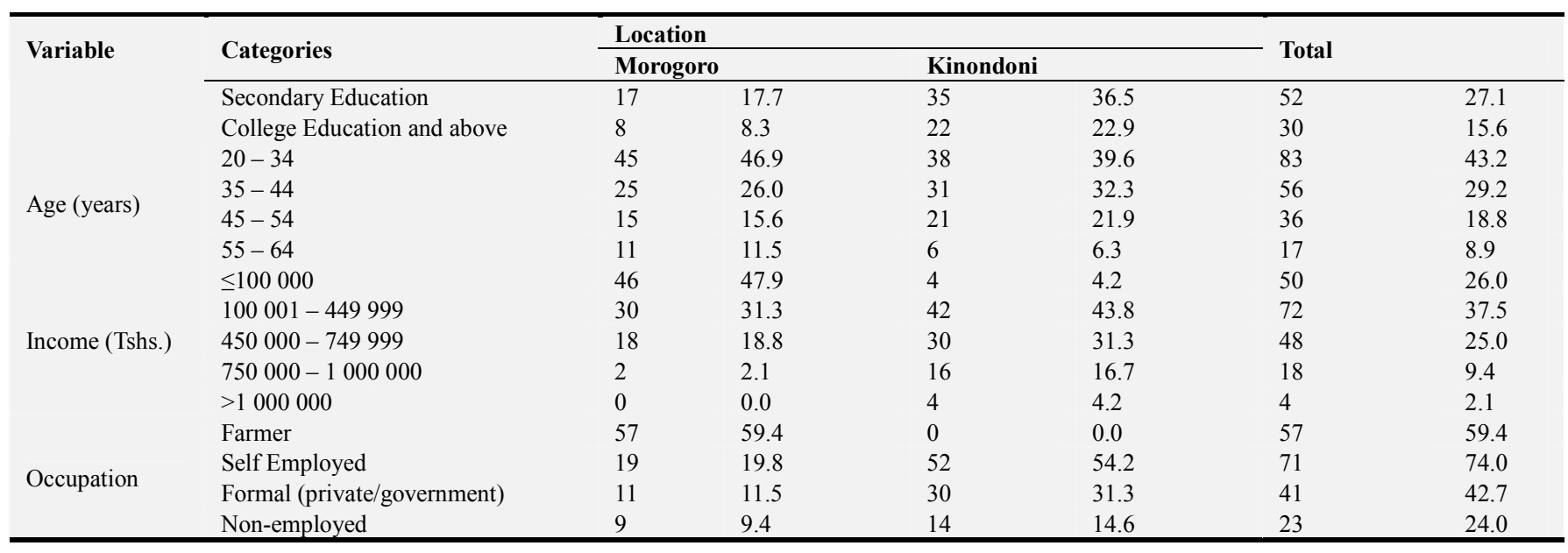

\subsection{Factors That Affect Consumers' Choice in Consumption of Organic Vegetables}

Table 2. Multiple regression of the factors affecting the purchase of organic vegetables.

\begin{tabular}{llll}
\hline Factor & Standardized Coefficient $\boldsymbol{\beta}$ & Standard error & $\boldsymbol{P}$ \\
\hline Uniqueness & 0.071 & 0.043 & 0.332 \\
Price & 0.021 & 0.048 & 0.781 \\
Availability & 0.032 & 0.057 & 0.781 \\
Shelf life & 0.108 & 0.046 & 0.661 \\
\hline
\end{tabular}

The results presented in (Table 2), it was found that the lower shelf life of organic vegetable was the main factor that affected by $10.6 \%$ the purchase of these foods compared to the lack of uniqueness $(4.3 \%)$, higher price $(2.1 \%)$ and lack of availability of organic vegetables at the market (3.2\%).

\subsubsection{Uniqueness of Organic Vegetables}

About $41 \%$ indicated that, there was no clear distinction between organic and conventional vegetables sold on the market (Table 3). This was higher in Kinondoni Municipality whereby more than half $(53.1 \%)$ of the respondents in the area were not able to distinguish between conventional and organic vegetable products. Only $28.1 \%$ of the respondents in Morogoro Municipality reported inability to distinguishing the two categories (Table 3 ).

Table 3. Factors affecting the purchasing of organic vegetables.

\begin{tabular}{|c|c|c|c|c|c|c|c|c|c|c|}
\hline \multirow{3}{*}{ Factor } & \multirow{3}{*}{ Response } & \multicolumn{4}{|c|}{ Location } & \multirow{2}{*}{\multicolumn{2}{|c|}{ Total }} & \multirow{3}{*}{$\mathbf{X}^{2}$} & \multirow{3}{*}{$d f$} & \multirow{3}{*}{$\boldsymbol{P}$} \\
\hline & & \multicolumn{2}{|c|}{ Morogoro } & \multicolumn{2}{|c|}{ Kinondoni } & & & & & \\
\hline & & $n=96$ & $\%$ & $n=96$ & $\%$ & $\mathrm{~N}=192$ & $\%$ & & & \\
\hline Uniqueness & Not unique & 27 & 28.1 & 51 & 53.1 & 78 & 40.6 & 12.47 & 1 & $0.00 * *$ \\
\hline Cost & More expensive & 68 & 70.8 & 69 & 71.9 & 137 & 71.4 & 0.025 & 1 & 0.87 \\
\hline Shelf life & Does stay longer & 61 & 63.5 & 24 & 25.0 & 85 & 44.3 & 28.90 & 1 & $0.00 *$ \\
\hline Availability & Insuffiecent at the market & 80 & 83.3 & 80 & 83.3 & 160 & 83.3 & 0.05 & 1 & $0.00 *$ \\
\hline
\end{tabular}

** The mean difference is significant at $P<0.001$

* The mean difference is significant at $P<0.01$

\subsubsection{The Cost of Purchasing Organic Vegetables in Morogoro and Kinondoni Markets}

About $71 \%$ of the respondents reported that the price of organic vegetables was higher than that of non-organic vegetables. More than $70 \%$ of the respondents in both locations claimed that they could afford to buy organic vegetable at a higher price (Table 3 ).

\subsubsection{Shelf-life and Availability of Organic Vegetables}

About $43.3 \%$ of the respondents in both locations reported that organic vegetables had a less shelf life than conventional vegetables. This study revealed that $83.3 \%$ in both localities, Morogoro and Kinondoni agreed that there is insufficient of organic food in the market (Table 3 ).

\subsection{Methods Used by Consumers to Avoid Consumption of Unhealthy Food}

The results of multiple regressions showed that, looking product physical appearance explained by $49.3 \%$, the least explained by $43.4 \%, 29.6 \%$ and $14.6 \%$, for asking sellers on product information, reading product labels for packing products, and tasting product, respectively (Table 4).

Table 4. Multiple regression analysis of the methods used by consumers to protect themselves from consumption of unhealthy foods.

\begin{tabular}{lll}
\hline Method & Standardized Coefficient $\boldsymbol{\beta}$ & Standard error \\
\hline Reading product labeled & 0.296 & 0.400 \\
Asking a seller for product information & 0.434 & 0.039 \\
Looking physical appearance & 0.493 & 0.039 \\
Tasting product quality & 0.146 & 0.056 \\
\hline
\end{tabular}




\subsubsection{Reading Food Product Labels}

The methods that are used by consumers in avoiding from consumption of unhealthy foods are indicated in (Table 5). It was observed that, less than half $(45.3 \%)$ of food, consumers in the studied population could read the label of the packed food product. Less than a quarter $(24 \%)$ of respondents in Morogoro Municipality read product labels before purchasing labeled food product.

Table 5. Methods used by consumers to avoid consumption of unhealthy foods.

\begin{tabular}{|c|c|c|c|c|c|c|c|c|}
\hline \multirow{3}{*}{ Method } & \multicolumn{4}{|c|}{ Location } & \multirow{2}{*}{\multicolumn{2}{|c|}{ Total }} & \multirow{3}{*}{$X^{2}$} & \multirow{3}{*}{$P$} \\
\hline & \multicolumn{2}{|c|}{ Morogoro } & \multicolumn{2}{|c|}{ Kinondoni } & & & & \\
\hline & $n=96$ & $\%$ & $n=96$ & $\%$ & $\mathrm{~N}=192$ & $\%$ & & \\
\hline Reading product label & 23 & 24 & 64 & 66.7 & 87 & 45.3 & 7.59 & 0.06 \\
\hline Asking the seller for product information & 22 & 22.9 & 52 & 54.2 & 74 & 38.5 & 19.76 & $0.00 * *$ \\
\hline Looking at physical appearances & 60 & 62.5 & 40 & 41.7 & 100 & 52.1 & 8.35 & $0.00 *$ \\
\hline Tasting product quality & 23 & 24 & 3 & 3.1 & 26 & 13.5 & 17.79 & $0.00 *$ \\
\hline Buying product without any assessment & 15 & 15.6 & 9 & 9.4 & 24 & 12.5 & 1.71 & $0.00^{*}$ \\
\hline
\end{tabular}

** The mean difference is significant at $P<0.0001$

*The mean difference is significant at $\mathrm{p}<0.001$

\subsubsection{Product Information}

The finding from this study showed that only $38.5 \%$ of the interviewed consumers in both locations were using this method of assessing product quality to protect themselves from consumption of unhealthy foods. The percent of consumers (Table 5) who could ask the sellers about product information in Kinondoni Municipality was greater (54.2\%) compared to those in the Morogoro Municipality (22.9\%).

\subsubsection{Looking at Physical Appearances}

About $52 \%$ of the respondents in Morogoro and Kinondoni municipalities avoided the consumption of unhealthy foods through physical observation and experience (Table 5). It was observed that $62.5 \%$ and $41.7 \%$ of food consumers in Morogoro and Kinondoni, respectively, used physical method of assessing food quality.

\subsubsection{Tasting Product Quality}

This study revealed that, less than a quarter of consumers used taste in assessing food quality to protect them from consuming unsafe foods. It was observed that, tasting was employed by $25 \%$ of respondents in Morogoro and only $3.1 \%$ of respondents in the Kinondoni Municipality (Table 5).

\subsubsection{Socioeconomic Status of Consumers}

The study revealed that more than $70 \%$ of those who had higher socioeconomic status were reading product labels and asking the sellers on the product information on packed food product. They used these methods as protection means for their health wellbeing. The methods were however not as popular as to those who had lower socioeconomic status, those who were earning TZS $<100000 /=$ per month (Figure 3).

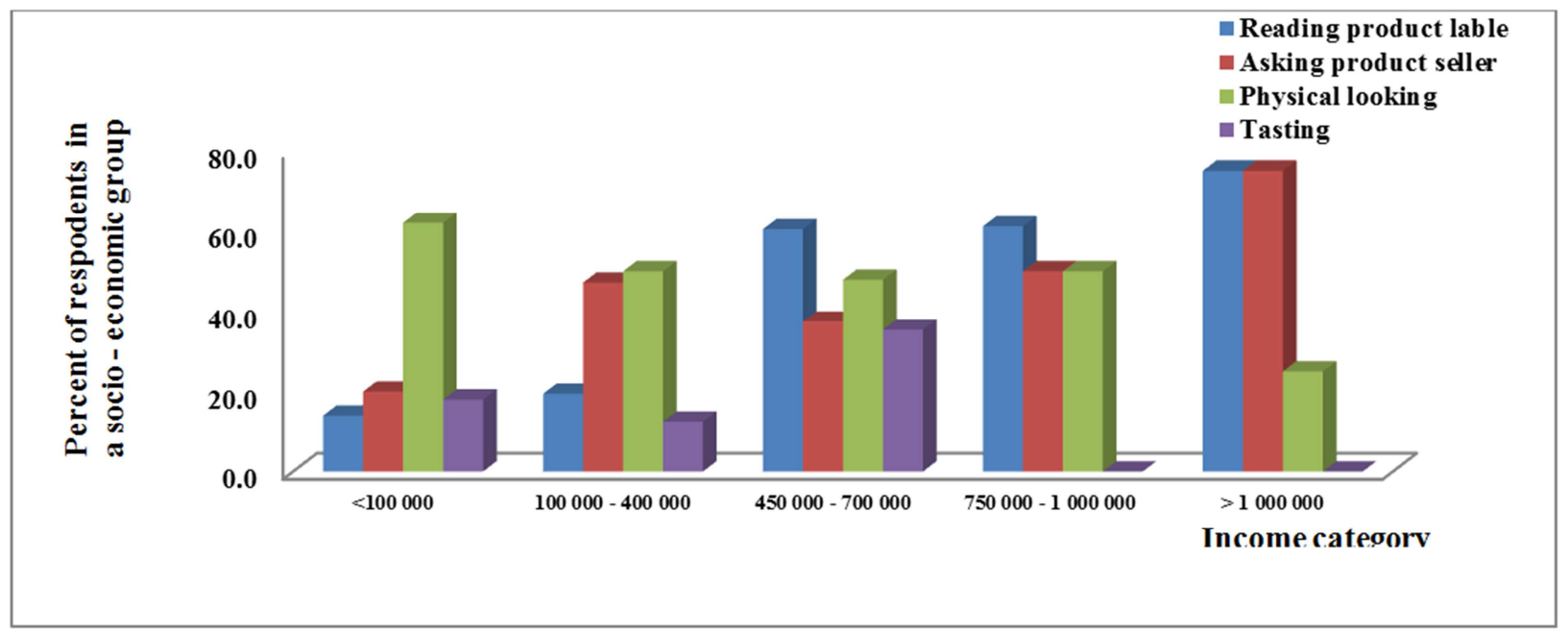

Figure 3. Socio economic status and protection means from consumption of unhealthy food.

\subsubsection{The need of Participatory Guarantee System (PGS)}

The recent finding of this study showed that, about $98 \%$ $(n=189)$ of the interviewed respondents preferred this system. Of these, $50.26 \%$ were in Morogoro area and the least were in Dar es Salaam (Figure. 4). It was found that, the number of those who preferred this system was, however, higher in Morogoro $(97.92 \% ; n=94)$ than these in Dar es Salaam $(88.96 \% ; n=95)$ area. 


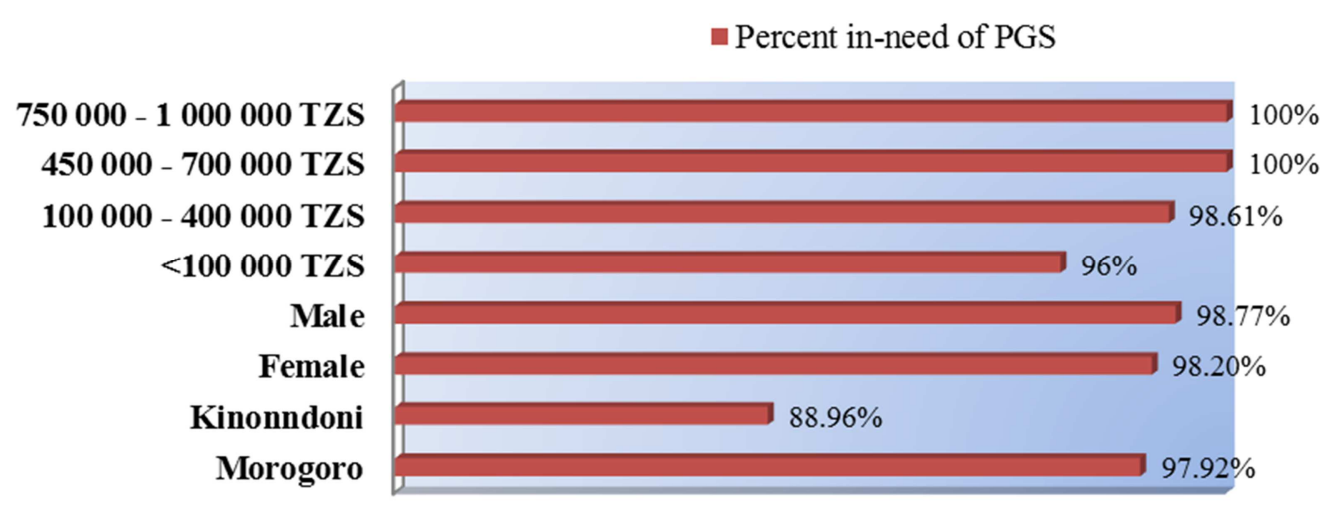

Figure 4. The percent of respondents who were in-need of PGS.

The results showed further that more than $98 \%$ of both females and males were also in need of this system (Figure. 4). It is also shown that, a large percent of those who had higher economic status were also in-need of this system as those who had lower economic status (Figure. 4).

\section{Discussion}

\subsection{Socioeconomic and Demographic Characteristics of the Farmers and Consumers}

\subsubsection{Sex of Farmers and Consumers}

In the current study, (Table 1) the proportional of females engaged in this study were actually higher than that of males in each of the locations. However, the proportional of males who were involved in Kinondoni Municipality was higher than that of Morogoro Municipality. Conversely, female respondents in Morogoro were higher than that of the same sex in Kinondoni area. This has an implication on organic vegetable purchases in this location. For example, [1] in their study of Southern Italy reported that, women were more concerned with purchase of organic foods than men.

\subsubsection{Age of the Respondents}

In both locations the number of the studied individuals at the age between $20-34$ was actually higher compared to other age groups (Table 1). The younger consumers are more likely to purchase organic products due to their preference for chemical free products and interest in environmental quality [25]. For example, younger Canadians tended to have a higher preference for chemical free products and therefore showed a higher preference for organic products, whereas older Canadians were less concerned about the complete elimination of chemicals [53]. In general, younger consumers tend to have a lower purchasing power than older consumers. [1] hypothesized that older consumers (i.e., More than 55 years) tend to make preventative health decisions, because of perceived health vulnerability as equated to young individuals and the awareness that they are generally at higher health risk than younger individuals [46]. On the other hand, [42] reported that the level of knowledge and use of food labeling information in purchasing organic vegetables among consumers increased with age, level of education and family income.

\subsubsection{Education Level}

Education status of an individual has a greater implication of knowledge and wellbeing as well. Most of the respondents who had a higher education level (at least college education) were in Kinondoni Municipality (Table 1). It was further found that, the number of secondary educated participants in Kinondoni was twice to those of Morogoro Municipality. Generally, participants in Kinondoni were much more educated than their counterparts in Morogoro area.

\subsubsection{Occupational of Consumers and Farmers}

Most of the studied populations in Morogoro Municipality were farmers (Table 1). This is because they were targeted for interviews. The rest in this area were self-employed in a non - farming sector like petty business or worked in the formal sector (including government and private sectors). Despite of the higher number of people being self-employed and worked in the formal sector in Kinondoni Municipality compared to their fellow in Morogoro area, the prevalence of unemployment in Kinondoni was higher as well. Such prevalence was actually higher compared to that reported by the census done in 2012 by the National Bureau of Statistics [29]. It ascertains the finding of others that farming activity remains a single working sector, which employs most people in the country [29; 8]. [28] Reported that people working full time are more likely to purchase organic food compared to part time or none. This was associated with the increasing income of the full time workers compared to the rest.

\subsection{Factors that Affect Consumers' Choice in Consumption of Organic Vegetables}

\subsubsection{Uniqueness of Organic Vegetables}

It was observed that consumers were not able to make a clear distinction among organic and conventional vegetables. The number of those who could not be able to distinguish these in Kinondoni was higher compared to that in the Morogoro Municipality (Table 3). The failure to distinguish between organic and conventional vegetables is caused by lack of awareness of consumers about them. [28] Reported that organic products are credence goods, consumers (unlike 
producers who are aware that their products are organic) may not know whether a product is produced using organic or conventional methods, not even after repeated purchase and consumption, unless they are told so [24]. Thus, awareness and knowledge about organically produced foods are critical in the consumer purchase decisions. If an individual cannot clearly differentiate between two alternative products, a price premium on the organic product can confuse and/or affect the individual's purchasing decision, in favor of the cheaper product. In developing countries, it's also attributed by lack of certification of producers and their products. Unlike in developed countries producers of organic vegetables are certified, smaller producers or large producers, both are certified [26]. This certification of organic food adds value to agricultural production.

\subsubsection{The Cost of Purchasing Organic Vegetables in Morogoro and Kinondoni Markets}

The cost of buying organic vegetable was reported to be much more expensive compared to their counterpart's vegetables in these locations (Table 3). [45] Observed that organic consumers have been normally willing to pay approximately $10 \%$ more over the conventional vegetables. [16] Reported that many consumers still prefer organic vegetables despite the premium price they have to pay for organic vegetables.

The general perception is that organic vegetables are superior over conventional vegetables, and the common attributes motivating organic consumers to pay higher prices are: organic vegetables are healthier than conventional vegetables, organic vegetables are tastier than conventional vegetables, organic vegetables are better quality than conventional vegetables, and organic vegetables have more human touch than conventional vegetables [16]. In addition, education level of the consumers plays a significant positive role. Educated people buy more organic vegetables than noneducated ones [16].

\subsubsection{Shelf-Life of Organic Vegetables}

This study has also revealed that many respondents thought that organic vegetables had a less shelf life than conventional vegetables (Table 3). One of the reasons accounting for the shorter shelf life could be due to the vulnerability of organic produce to bacteria build-up as opposed to conventional fruits and vegetables treated with the chemicals for more resilience, during growth and thereafter [7]. However, according to the field observations, both organic vegetables and conventional vegetables had the same shelf life [7].

\subsubsection{Availability of Organic Vegetables}

The availability of organic vegetables in the local market is still unquestionable in both areas - as consumers complained they are not easily found in the local markets (Table 3). This creates opportunities of organic market. Majorities were complaining that they did not know where to get organic vegetables. [5] Reported that product availability was key inhibitors to consumers' demand for organic vegetables in
Ireland as two-thirds of non-buyers of organic food would buy organic if it was easily available. Long distance walking, looking for organic food brings barriers to consumers of organic vegetables, always a consumer goes for shopping at a nearby home [28].

\subsection{Methods Used by Consumers to Avoid Consumption of Unhealthy Foods}

Consumers use different methods in avoiding consumption of foods that could otherwise harm their wellbeing [31]. These methods are categorized in two ways: traditional methods such as physical observation of color, shape, environment at which food/food product is placed, the taste of the food, and textural feelings and modern technology methods such as product labeling and other laboratory analytical methods [4].

Despite the existence of various methods in assessing product quality to protect consumers from consumption of harmful foods, some consumers did not use any of these methods. Therefore, it was observed that, the number of those who do not check for the product quality in Morogoro was higher as compared to their counterparts in Kinondoni Municipality.

\subsubsection{Reading Food Product Labels}

It was observed that there were a higher number of people who could use label identification in Kinondoni Municipality compared to those in Morogoro (Table 5). This implied that consumers have high awareness of food labeling and thus, it assisted consumers to make informed choices during purchase of food. This finding came into an agreement with that of [20] who reported more than forty percent of the studied consumers could not read on the packed food product. The reason given to this was the lack of time to read the food product.

Nevertheless, in spite of this difference, results showed that, there was no significant difference $(P>0.05)$ in the use of this method among people in Kinondoni and Morogoro municipalities (Table 5). [42 and 47] reported that, only a few of the food consumers tend to use this method as to protect their health wellbeing. [42] reported that, reading food product label for packed food product is not taken into much consideration, not only by those who cannot be able to read the written product information on the food label, but also even those who could be able to read the product label. [39] Reported that reading food labeling occasionally, particularly women, dietary restrictions people and those with at least a kind of food and nutrition knowledge of the link between diet and disease check food labeling information.

\subsubsection{Product Information}

Product information is not only linked to product quality, but also its originality [9]. Some buyers would wish to ask the product seller on product descriptions that were linked to the sold product (Table 5). Consumers generally perceive an organic label as assurance that the product was organic. More accurately, organic food labels help transform the credence characteristics 
of such products into search attributes, thereby allowing the consumer to better evaluate the quality before deciding to buy the product [13]. In addition to that, [42] reported that the level of knowledge and use of food labeling information in purchasing foods among consumers increased with age, level of education and family income. A study in Northern Thailand also found that willingness to pay for 'safe' vegetables increases with age and income [23].

\subsubsection{Looking at Physical Appearances}

Looking physical appearance of the food product in these locations was a common method as compared to tasting product quality with higher number of those using this kind of method in Kinondoni compared to those in Morogoro (Table 5). [28] Observed that quality assessment of food product through physical observation created barriers to organic food consumption. The organic food sometimes could be unattractive in comparison with conventional product and consequently fetch a lower market price [28].

\subsubsection{Tasting Product Quality}

Eating food was a general motive for everybody to satisfy the needs. Most consumers thought that organic products taste more natural, intense and rich in flavor [28]. Food tasting was one of the methods used in the assessment of aromatic characteristics of specific food quality [22]. The method may be affected by age and health of an individual. As one ages, the sense of taste is also affected, thus raising the threshold level of an individual in sensory evaluation [18]. In addition, some individuals have higher ability in differentiating food products, even in the presence of small changes of organoleptic quality trait concentration [24]. Many organic buyers believe that organic produce tastes better than conventionally grown produce, even if sensory evaluations yield inconsistent results [52]. In the current study, using this method among respondents in these areas was significantly different $(P<0.05)$ (Table 5$)$. This implied that they use other methods apart from taste.

\subsubsection{Socioeconomic Status of Consumer}

Reading product label and asking the sellers on the product information on packed food product were common methods used by the majority of higher socioeconomic status costumers in protecting themselves from eating unhealthy foods (Figure. 3). Many individuals with higher educational achievements tend to also have higher incomes and thus increasing the likelihood of purchasing organic products. In contrast, [51], reported that income is not a significant variable in explaining differences in the purchasing behavior of buyers and non-buyers of organic products, and thus income had no significant influence on willingness to pay for organic.

\subsubsection{The Need of Participatory Guarantee System (PGS)}

Not only farmers, but also vegetable consumers of these areas preferred PGS (Figure. 4). Though there was no significance difference between the two locations $\left(\mathrm{X}^{2}=3.39\right.$; $d f=1 ; P=0.561)$, the number of people welcoming this system in Morogoro was higher compared to those in
Kinondoni Dar es salaam. The results of the present findings showed that, there was no significance differences in-need of PGS between males and females, and among people of different socioeconomic status $(\mathrm{P}>0.05)$ (Figure 4). One of the reasons to why most of the people were in-need of the PGS in Morogoro than in Dar es salaam City is due to higher number of people (farmers) who were actively engaged in PGS in this area and its rural characteristics than Dar es salaam, which in most cases is business oriented city. With this observation, it might also be due to a large number of farmers who were actively engaged in organic farming in this area, but lacking special market for their producers and thus selling them at lower prices in respective to production cost they incur in the production process. Therefore, most of the farmers might be motivated with this system if it is established with their locality.

PGS may be an alternative method for the most farmers who were actively engaged with organic producers in Morogoro than being certified by certification bodies, as its certification is associated with higher fees of which most of lower socioeconomic farmers cannot be able to afford [6]. Establishing PGS with organic growers in the study area is as much important for the success of small-scale farmers, due to better support systems and networks among them. The implementation of PGS in other areas as observed in other studies was successful among small-scale farmers and largescale farmers. Hence organic farmers must unite so as to share their challenges and success and how to overcome them [6 and 15].

\section{Conclusion}

Looking physical appearances of food product was a common method used by most consumers to protect them from eating of unhealthy foods. Some were reading product labels for packing food products, asking sellers on food product information and food tasting. With the exception of food labeling, the use of these methods varied significantly $(P<0.05)$ among people in Morogoro and Kinondoni municipalities. Most (97\%) of the farmers for organic vegetables affirmed to welcome participatory guarantee methods for their food produces as for liable markets.

It is recommended that other studies should be done to investigate other methods that will be used by consumers to avoid consumption of unhealthy foods. Furthermore, for most farmers of organic vegetables in Morogoro are considerably welcoming the participatory guarantee system to assure them with their produce market availability. It is recommended that investors should cooperate with them for business-oriented aspects.

\section{References}

[1] Annunziata, A. and Vecchio, R. (2016). Organic farming and sustainability in food choices: an analysis of consumer preference in Southern Italy. Journal of Agriculture and Agricultural Science Procedia, 8: 193-200. 
[2] Arbenz, M., Gould, D. and Stopes, C. (2016). The world of organic agriculture. Statistics and emerging trends 2016. ISOFAR international organic EXPO 2015, Goesan county. [https://shop.fibl.org/fileadmin/documents/shop/1698-organicworld-2016.pdf] site visited on 23/ 06/2016.

[3] Bartlett, E. J., Kotrlink, W. J. and Higgins, C. C. (2001). Organizational research: Determining appropriate sample size in survey research. [https://www.

researchgate.net/publication/200824035_organizational_resear ch_determining_appropriate_sample_size_in_survey_research ] site visited on $07 / 06 / 2015$.

[4] Benbrook, C. and Davis, R. D. (2011). Identifying smart food choices on the path to healthier diets. Available [https://organic-center.org/reportfiles/TOC-NQI Methodology_Final_9-10-11.pdf] site visited on 08/09/2016.

[5] Dickieson, J. A., Arkus, V. and Wiertz, C. (2009). Factors that influence the purchase of organic food: A study of consumer behaviour in the UK. [www.ein-herz-fuerbio.org/sites/default/files/downloads/dickiesonj_arkusv.pdf] site visited on $08 / 07 / 2016$.

[6] Dimitri, C. and Dettmann, R. (2012). Organic food consumers: What do we really know about them? Brazilian. Food Journal, 114: 1157-1183.

[7] Erman, E. (2015). Does organic produce spoil faster than conventional? [http://www.organicauthority.com/doesorganic-produce-spoil-faster-than-conventional/] site visited on $23 / 04 / 2016$.

[8] Export Promotion of Organic Products from Africa (EPOPA) (2004). Basic data on certified organic production and export in Tanzania 2003. [www.grolink. se/epopa/.../Org\%20Prod\%20and\%20Exp\%20TZ-03.pdf] site visited on 03/05/2015.

[9] FAO (2010). Linking people, places and products: A guide for promoting quality linked to geographical origin and sustainable geographical indications. [http://www.fao.org/docrep/013/i1760e/i1760e.pdf] site visited on $02 / 05 / 2016$.

[10] FAO (2012). Organic Agriculture and the Law. [http://www.fao.org/docrep /016/i2718e/i2718e.pdf] site visited on 12/09/2016.

[11] FiBl and International Federation of Organic Agriculture Movement (IFOAM) (2015). Growth continues: Global organic market at 72 billion us dollars with 43 million hectares of organic agricultural land worldwide. [http://www.ifoam.bio/sites/

default/files/ifoam_pr_2015_02_10_world_of_organic_agricu lture.pdf] site visited on $10 / \overline{0} / 2016$.

[12] FiBl and International Federation of Organic Agriculture Movement (IFOAM) (2013). Organic Agriculture Worldwide: Key results from the FiBL-IFOAM survey on organic agriculture worldwide 2013 Part 2: Crop data [http://orgprints.org/ 22349/22/fibl-ifoam-2013-crops2011.pdf] site visited on 12/6/2016.

[13] Hamm, U. and Janssen, M. (2012). Product labelling in the market for organic food: Consumer preferences and willingness-to-pay for different organic certification logos. Journal of food quality and Preference, 25 (1): 9-22.

[14] Huber, M., Rembiałkowska, E., Średnicka, D., Bügel, S. and Vijver, L. P. L. (2011). Organic food and impact on human health: Assessing the status quo and prospects of research. [http://www.sciencedirect.com/science/article/pii/ S1573521411000054] site visited on 10/09/2016.

[15] Hughner, R. S., McDonagh, P., Prothero, A., Shultz, C. J. and Stanton, J. (2007). Who are organic food consumers? A compilation and review of why people purchase organic food. Journal of Consumer Behavior, 6: 1-17.

[16] Islam, S. (2013). Retail price differential between organic and conventional vegetables. [asbbs.org/files/ASBBS2013/PDF/I/IslamS(P537-545).pdf] site visited on $07 / 09 / 2016$.

[17] Kato, T. (2013). Impact of agricultural input subsidies on poverty in Tanzania: REPOA's $18^{\text {th }}$ Annual Research. [www.repoa.or.tz/documents_storage/GD3.pdf] site visited on $10 / 09 / 2016$.

[18] Kemmet, D. and Brotherson, S. (2015). Making sense of sensory losses as we age: childhood, adulthood, elder hood? [https://www.ag.ndsu.edu/pubs/yf/ famsci/fs1378.pdf] site visited on 10/09/2016.

[19] Kothari, C. R. (2009). Research Methodology: Methods and Techniques. University of Rajasthan Jaipur, India. 401pp.

[20] Lagerkvist, J. C. (2013). Consumer preferences for food labelling attributes: Comparing direct ranking and best-worst scaling for measurement of attribute importance, preference intensity and attribute dominance. Journal of Food Quality and Preference, 29 (2): 77-88.

[21] Larson, F., Muraoka, R. and Otsuka, K. (2016). Why African rural development strategies must depend on small farms. Journal of global Food Security, 10: 39-51.

[22] Magee, H. (2009). Talking about taste: How the description of food means and does? [https://www.swarthmore.edu/.../default/.../2009_Mag...] site visited on 29/04/2016.

[23] Magistris, D. T. and Gracia, A. (2016). Consumers' willingness-to-pay for sustainable food products: the case of organically and locally grown almonds in Spain. Journal of Cleaner Production, 118: 97-104.

[24] Matt, D., Rembialkowska, E., Luik, A., Peetsmann, E. and Pehme, S. (2011). Quality of organic vegetables. conventional vegetables and effects on health [orgprints.org/19504 /1/Report_2011_(1).pdf] site visited on 21/04/2016.

[25] Michaelidou, N. and Hassan, M. L. (2010). Modeling the factors affecting rural consumers' purchase of organic and free-range produce: a case study of consumers' from the Island of Arran in Scotland, UK. Journal of Food Policy, 35 (2): 130-139.

[26] Misner, S. and Florian, A. T. (2013). Organically grown foods versus non-organically grown foods. [extension.arizona.edu/pubs/az1603.pdf] site visited on 05/08/2016.

[27] Moshi, P. A. and Matoju, I. (2016). The status of research on and application of bio pesticides in Tanzania. Review. Journal of Crop Protection, 92: 16-28.

[28] Mutlu, N. and Becker, T. (2007). Consumer attitude and behavior towards organic vegetables: Cross-cultural study of Turkey and German. [orgprints.org/ 13727/1/MasterThesisConsumerStudy-TR-DE.pdf] site visited on 05/06/2016. 
[29] National Bureau of Statistics (NBS) (2014). Basic demographic and socio-economic profile statistical tables Tanzania mainland. Ministry of Finance Dar es Salaam. [http://www.tanzania.go.tz/egov_uploads/documents/TANZA NIA MAINLAND_SOCIO_ECONOMIC_PROFILE_sw.pdf] site visited on $12 / 8 / 2015$.

[30] National Organic Agriculture Forum (NOAF) (2008). National organic agriculture development programme for Tanzania 2009-2015. [www.kilimohai.org] site visited on 07/09/2016.

[31] Naughton, P., McCarthy, M. and McCarthy, S. (2015). Acting to self-regulate unhealthy eating habits. An investigation into the effects of habit, hedonic hunger and self-regulation on sugar consumption from confectionery foods. Journal of Food Quality and Preference, 46: 173-183.

[32] Ngowi, A. V. F., Mbise, T. J., Ijani, A. S. M., London, L. and Ajayi, O. C. (2008). Pesticides use by smallholder farmers in vegetable production in Northern Tanzania. Journal of Science Total Environment, 26 (11): 1617-1624.

[33] Nonga, H. E., Mdegela, R. H., Lie, E., Sandvik, M. and Skaare, J. U. (2011). Assessment of farming practices and uses of agrochemicals in Lake Manyara basin, Tanzania. African Journal of Agricultural Research, 6(10): 2216-2230.

[34] Paul, V. U., Lossini, S. J., Edwards, J. P. and Hilberck, A. (2009). Effectiveness of products from four locally grown plants for the management of Acanthoscelidesobtectus (Say) and Zabrotessubfasciatus (Boheman) (both Coleoptera: Bruchidae) in stored beans under laboratory and farm conditions in Northern Tanzania. Journal of Stored Products Research, 45: 97-107.

[35] Pesticide and Poverty Report Tanzania (2006). A case study on trade and utilization of pesticides in Tanzania: Implication to stockpiling. [http://www.pan-uk.org /archive/projects/obsolete/15.\%20trade and utilization_of pe sticides_in_tanzania_final.pdf] site visited on 10/09/2016.

[36] Research Institute of Organic Agriculture (FiBL) and International Federation of Organic Agriculture Movement (IFOAM) (2013). Organic agriculture worldwide: Key results from the FiBL-IFOAM survey on organic agriculture worldwide 2013. global data and survey background. [orgprints.org/22349/28/fibl-ifoam-2013-global-data2011.pdf] site visited on 14/07/2016.

[37] Research Institute of Organic Agriculture (FiBL) and International Federation of Organic Agriculture Movement (IFOAM) (2015). World of organic agriculture. [https://www.fibl.org/fileadmin/documents/shop/1663organic-world-2015.pdf] site visited on 10/09/2016.

[38] Robinson, R. O., Larson, N., Dianne, N. S., Peter, H. and Story, M. (2009). Characteristics and dietary patterns of adolescents who value eating locally grown, organic, nongenetically engineered, and non-processed food. Journal of Nutrition Education Behavior, 41(1): 11-18.

[39] Roos, G., Kjærnes, U. and Ose, T. (2010). Warning labels on food from the point of view of the consumers. [https://www.mattilsynet.no/ mat_og_vann/ merking_av_mat/ allergener] site visited on 09/08/2016.

[40] Rosinger, C. (2013). Organic agriculture and certification in Eastern Africa: a theoretical analysis with special reference to food security issues in Tanzania. Available at [http://www.shabka.org/wp-content/uploads/2013/05/ShabkaBackground 2-2013 Organic-agriculture-and-certification-in-
Eastern-Africa.pdf] site visited on 10/08/2016.

[41] Ruhl, L. H. (2013). Slow food: From farm to healthy body. [http://digitalcommons.

library.umaine.edu/cgi/viewcontent.cgi?article $=1130 \&$ context $=$ honors] site visited on $02 / 08 / 2016$.

[42] Samson, G. (2012). Awareness of food labeling and use of the information in purchasing prepackaged food products among consumers in Ilala municipality Dar es -Salaam. [http://ihi.eprints.org/1641/1/GWANTWA_SAMSON.pdf] site visited on $07 / 06 / 2016$.

[43] Shepherd, R., Magnusson, M. and Sjoden, P. O. (2005). Determinants of consumer behavior related to organic vegetables. A Journal of Human Environment, 34(4): 352-359.

[44] Tulchinsky, H. T. and Varavikova, A. E. (2014). Nutrition and Food Safety. New Public Health (Third Edition), academic press California. [http://www. sciencedirect.com] site visited on $08 / 09 / 2016$.

[45] Urena, F., Bernabeu, R. and Olmeda, M. (2008). Women, men and organic vegetables. Differences in their attitudes and willingness to pay. A Spanish case study. International Journal of Consumer Studies, 32: 18-26.

[46] Vecchio, R., Loo, J. V. E. and Annunziata, A. (2016). Consumers' Willingness to Pay for Conventional, Organic and Functional yogurt: evidence from experimental auctions. International Journal of Consumer Studies, 40(3): 368-378.

[47] WHO (2004). Nutrition labels and health claim. the global regulatory environment.

[whqlibdoc.who.int/.../2004/9241591714.pdf] site visited on 10/09/2016.

[48] WHO (2015). Food safety: What you should know. World health day. [http://www.searo.who.int/entity] site visited on $10 / 07 / 2016$

[49] Willer, H. and Kilcher, L. (2012). World of organic agriculture - Statistics and emerging trends 2009. International Federation of Organic Agriculture Movements (IFOAM) and Research Institute of Organic Agriculture (FiBL). [http://orgprints.org/18380/16/willer-kilcher-2009.pdf] site visited on $08 / 6 / 2015$.

[50] Willer, H. and Youssefi, M. (2007). World of organic agriculture - Statistics and emerging trends 2008. International Federation of Organic Agriculture Movements (IFOAM) \& Research Institute of Organic Agriculture (FiBL). [http://orgprints.org/13123/4/world-of-organic-agriculture2008.pdf] site visited on 14/06/2015.

[51] Yi, K. L. (2009). Consumer behaviour towards organic food consumption in hong Kong: an empirical study. [libproject.hkbu.edu.hk/trsimage/hp/06011446.pdf] site visited on $05 / 09 / 2009$.

[52] Zhao, X., Chambers, E., Matta, Z., Loughin, T. and Carey, E. (2007). Consumer sensory analysis of organically and conventionally grown vegetables. Journal of Food Science, 72: 87-91.

[53] Macknnon, S. (2013). The national organic market. growth, trends and opportunities, 2013. Agriculture and agri-food Canada. [https://ota.com/ sites/default/files/ indexed_files/COTA_nationalorganicmarketsummary.pdf] site visited on $26 / 09 / 201 \overline{6}$ 